
\title{
28 Research Square \\ Validity of A Mobile Phone based Application Tool for COVID-19 Screening Test
}

\section{Mahteme Bekele Muleta ( $\square$ mahtemebekele@gmail.com )}

SPHMMC: St Paul's Hospital Millennium Medical College https://orcid.org/0000-0003-0916-9008

\section{Mebratu Abrha Kebede}

St Paul's Hospital Millennium Medical College

Abrham Getachew Dullo

St Paul's Hospital Millennium Medical College

\section{Adugna Lissanewerk Mekonnen}

St Paul's Hospital Millennium Medical College

Thomas Shimelis

St Paul's Hospital Millennium Medical College

\section{Brhane Tegegn}

Google Inc

\section{Natnael Taye}

St Paul's Hospital Millennium Medical College

\section{Addisu Gize}

St Paul's Hospital Millennium Medical College

\section{Tariku Shimelis}

St Paul's Hospital Millennium Medical College

\section{Yifru Berhan}

St Paul's Hospital Millennium Medical College

\section{Research article}

Keywords: mobile application tool, sensitivity, specificity, validity, COVID-19, Ethiopia

Posted Date: July 9th, 2021

DOI: https://doi.org/10.21203/rs.3.rs-684797/v1

License: (c) (i) This work is licensed under a Creative Commons Attribution 4.0 International License. Read Full License 


\section{Abstract}

Background: The COVID-19 outbreak is proving to be a unique disaster in many countries across the globe. Screening and diagnosis are challenges in resource-limited countries as confirmation with reverse-transcriptase polymerase chain reaction (RT-PCR) is expensive and less accessible. Besides, due to the overlapping manifestations, there are no strongly suggestive symptoms that can be used as a screening tool. The goal of this study was to assess the validity of a newly created mobile phone application tool as a COVID-19 screening approach to the gold standard test (RT-PCR).

Methods: An institution-based cross-sectional study was conducted among 1029 individuals for validity assessment of a newly developed COVID-19 screening tool by having PCR test results as a reference. After obtaining consent, data were collected using a structured questionnaire, maintaining all the COVID 19 prevention protocols. SPSS version 25 was used to analyze the data. The sensitivity and specificity of the tool were determined.

Result: A total of 1005 participants were included in the study, which made the response rate close to $98 \%$. The mean age of the respondents was $50.8(S D=17.32)$ years; $574(57.1 \%)$ were males and $108(10.7 \%)$ were in the age category of 41 years and above. The current study identified that the internal consistency of Cronbach's a was 0.769 . The validity analysis result of the tool revealed that it has a sensitivity of $77.6 \%$ with $31.6 \%$ of positive predictive value and specificity of $t 46.4 \%$ with $86.5 \%$ of negative predictive value. This study revealed that $59.4 \%$ of the study participants showed COVID-19 related symptoms and classified as tested positive for the infection, based on the newly developed mobile phone COVID-19 screening tool, whereas only $24.4 \%$ of them had positive test results for COVID-19 infection.

Conclusion: The sensitivity and specificity of the mobile application tool for symptomatic COVID 19 patients was almost equivalent to the nasal swab RT PCR test. Therefore, we recommend the use of this screening test bot. It is easily accessible and hence an effective way of reaching the population affected by the disease for early detection of symptomatic patients and taking appropriate measures.

\section{Background}

In late December of 2019, a cluster of cases of viral pneumonia of unknown aetiology was reported in Wuhan, Hubei Province, which was later identified and referred to as COVID-19Coronavirus Disease 2019) by WHO. It was caused by the novel SARS-CoV-2 (Severe Acute Respiratory Syndrome Coronavirus-2) that was able to spread rapidly and developed into a global pandemic level within a few months (1-3). Reported symptoms include fever, cough, fatigue, pneumonia, headache, Gastrointestinal (GI) upset (abdominal cramp, nausea/ vomiting or diarrhoea, hemoptysis, and dyspnea which resemble respiratory illnesses caused by other viruses or bacteria (4-5). Masks, hand hygiene procedures, avoidance of public interaction, case identification, contact tracing, and quarantines have all been mentioned as possible ways to scale back transmission(6).

The COVID-19 outbreak is proving to be an exceptional disaster in the most afflicted countries, including the USA, Brazil, Italy, Iran, and China in all aspects, especially the health, social, and economic disasters (7). The current interventions on COVID-19 mainly focused on infection control and the use of effective vaccine (8-9); there is no effective specific antiviral treatment (6). Clinical diagnosis is difficult due to the coinciding symptoms, particularly during the flu season. That is why the confirmation of COVID-19 depends on the detection of SARS-CoV-2 nucleic acid by reverse-transcriptase polymerase chain reaction (RT-PCR) (10). 
Infection prevention strategies and patient management depend on the accurate and timely COVID-19 test capacity. This enables or will assist the efforts which are aimed at controlling or slowing down the rapid transmission of the pandemic in the population and at the healthcare facilities (11). According to the recommendation of the World Health Organization (WHO), COVID-19 diagnosis can be made by molecular tests which detect the SARS-CoV-2 virus RNA. However, this test is difficult to perform because it necessitates committed health system with continuous delivery of numerous reagents, expensive laboratory equipment, and trained laboratory technologist. Currently, infrastructure limitations and supply shortages are limiting the testing capacity below the growing request for COVID-19 diagnostics across the world (12).

As a result, having access to consistent rapid diagnostic tests could relieve laboratory pressure and enhance testing capacity to meet the most pressing medical and public health needs (12). Regardless of symptoms, a case of COVID-19 is considered "confirmed" when a positive laboratory test for SARS-Cov-2 virus infection is obtained. Many diagnostic tests are currently available, and more are being accepted for emergency use on a daily basis. The majority of these tests are based on four main procedures: Reverse transcription-polymerase chain reaction (RTPCR), Loop-mediated isothermal amplification (LAMP), Lateral flow and Enzyme-linked immunosorbent assay (ELISA) (13). These tests are not easily accessible to the low income countries. Therefore, the need for a simple firstline screening tool is a crucial step for lowest-income countries, such as Ethiopia.

In Ethiopia, in particular, the need for proactive population screening for COVID-19 is extremely important as the general public seems to be reluctant to adhere to the preventive measures. Health care workers and community members alike are faced withthe important challenge of quickly identifying symptoms and taking appropriate steps for laboratory investigation in line with the case definition based on surveillance or clinical characterization. Therefore, developing a quick and valid instrument or tool to capture an individual's COVID-19 like symptoms is important and timely. As a result, the aim of this study was to evaluate the sensitivity and specificity of a newly developed COVID-19 screening test mobile phone based application tool in order to promote its widespread use.

\section{Methods And Materials}

\section{Study design, setting, period, and population}

A hospital and community-based cross-sectional analysis was designed to determine the validity of a newly developed mobile phone-based screening program. Individuals who came to the COVID-19 testing centers for various purposes were tested for COVID-19 infection symptoms using a standardized questionnaire that was included in the mobile-based screening application. The study participants were those who were suspected as case of COVID-19 by clinicians and isolated in the emergency unit; had contact history with COVID 19 positive individuals; had comorbid illnesses, and required to have preadmission screening or self-interest to be tested for COVID-19. Then, their result was compared with the result of RT PCR performed at St. Paul's Hospital Millennium Medical College.

\section{Sample Size Determination And Data Collection Methods}

The sample size was determined by using PASS software. Considering this study as a screening test, the following assumptions were duly considered: Power of $80 \%$, alpha value of 0.05 , a prevalence of $5 \%$, a desired sensitivity of $99 \%$, and $10 \%$ of non-response rate. A total of 1029 samples were included. The variables collected include a combination of demographic data such as age, sex, common symptoms of COVID-19, fever, cough, Shortness of breath, sore throat, easy fatigability, headache, anosmia/or Ageusia, GI upset ( either vomiting/ nausea/or diarrheal) 
travel history, contact history, and the presence and absence of co-morbidities such as diabetes mellitus, cardiovascular, lung, renal and liver diseases.

The researchers have also done a reliability analysis to measure the correctness of the tool that helps to what extent does the current tool would give consistent or dependable results during multiple trials in which a total of eight variables/items were included. The variables were, cough, shortness of breathing (SOB), sore throat, fever, anosmia, headache, easy fatigability, and vomiting are the symptoms that we used to develop the COVID-19 infection screening tool.

\section{Data Presentation:}

Result of the screening test is defined into two different categories for validation purposes and further subcategorized into two population groups for recommendation purpose following the screening result.

Category 1: Screening results suggestive of presence COVID 19 in patients who exhibit COVID 19 like symptoms. Category 2: Screening result Suggestive of absence of COVID 19 disease, in patients who did not exhibit COVID 19 like symptoms.

\section{Data Analysis}

The currently used software automatically transfers the data to a database. Data collected were saved on the web and were checked for flaw every day during data collection; completeness was checked, cleaned, and saved in a separate file, while the raw data remained in the main database.

Sensitivity, specificity, positive and negative predictive values of the screening test was compared with the gold standard laboratory PCR test results using two by two tables of measure of diagnostic validity (14).

\section{Result}

\section{Socio-demographic characteristics of the respondents}

A total of 1005 participants were included in the study which makes the response rate $97.7 \%$. The mean age of the respondents was $37(S D=15.62)$ years. Among the respondents, $574(57.1 \%)$ were males and choric medical illness presented in $191(19 \%)$ of the participants. Only $238(23.7 \%)$ of them had history of contact with an individual who had confirmed COVID-19 infection (Table 1). 
Table 1

-Description of socio demographic and clinical factors among individuals who underwent COVID-19 test, Addis Ababa, Ethiopia, 2020.

\begin{tabular}{|llll|}
\hline Variables & & Frequency & Percent (\%) \\
\hline Age & $<29$ & 389 & 38.7 \\
\hline & $30-39$ & 250 & 24.9 \\
& $40-49$ & 147 & 14.6 \\
\hline & $50-59$ & 105 & 10.4 \\
\hline Sex & $>60$ & 114 & 11.3 \\
\hline & Female & 431 & 42.9 \\
\hline Chronic medical illness & present & 191 & 57.1 \\
\hline & Mbsent & 814 & 81 \\
\hline Contact History & No & 767 & 76.3 \\
\hline & Yes & 238 & 23.7 \\
\hline Total & & 1005 & 100 \\
\hline
\end{tabular}

\section{Mobile screening and RTPCR test results of the study participants}

This study revealed that 597 (59.4\%) of the study participants showed COVID-19 related symptoms and classified as tested positive for the infection, based on the mobile COVID-19 screening tool. Of those who underwent RTPCR test, only 245 (24.4\%) had positive test results for COVID-19 infection (Fig. 1).

\section{Reliability And Validity Of The Tool}

The internal consistency of Cronbach's a was 0.769. Principal components factor analysis (PCA) was done to include items that best fit to the data and a total of seven items which had value greater than one were extracted (Table 2). Then, validity analysis was done by including the remaining eight items. Further, item correlation analysis was done and all of the selected items had Cronbach alpha of above 70 (Table 3). Further correlation analysis in between the symptoms was conducted and the result shows a significant correlation among each other at 0.01 level of 2-tailed (Table 4). The current validity analysis result revealed that sensitivity of the tool was $77.6 \%$ with $31.6 \%$ of positive predictive value. Specificity of the tool was $46.4 \%$ with $86.5 \%$ negative predictive value (Fig. 2). 
Table 2

Extraction Method by using principal components factor analysis result of the mobile phone based application COVID-19 test tool

\begin{tabular}{|c|c|c|c|c|c|c|}
\hline \multicolumn{7}{|c|}{ Total Variance Explained } \\
\hline \multirow[t]{2}{*}{ Component } & \multicolumn{3}{|c|}{ Initial Eigenvalues } & \multicolumn{3}{|c|}{ Extraction Sums of Squared Loadings } \\
\hline & Total & $\%$ of Variance & Cumulative \% & Total & $\%$ of Variance & Cumulative \% \\
\hline 1 & 2.430 & 14.292 & 14.292 & 2.430 & 14.292 & 14.292 \\
\hline 2 & 1.570 & 9.237 & 23.529 & 1.570 & 9.237 & 23.529 \\
\hline 3 & 1.503 & 8.841 & 32.369 & 1.503 & 8.841 & 32.369 \\
\hline 4 & 1.324 & 7.791 & 40.160 & 1.324 & 7.791 & 40.160 \\
\hline 5 & 1.255 & 7.382 & 47.542 & 1.255 & 7.382 & 47.542 \\
\hline 6 & 1.091 & 6.417 & 53.960 & 1.091 & 6.417 & 53.960 \\
\hline 7 & 1.027 & 6.043 & 60.003 & 1.027 & 6.043 & 60.003 \\
\hline 8 & 1.019 & 5.995 & 65.997 & 1.019 & 5.995 & 65.997 \\
\hline 9 & .921 & 5.416 & 71.413 & & & \\
\hline 10 & .858 & 5.049 & 76.462 & & & \\
\hline 11 & .823 & 4.840 & 81.302 & & & \\
\hline 12 & .754 & 4.433 & 85.735 & & & \\
\hline 13 & .632 & 3.721 & 89.455 & & & \\
\hline 14 & .569 & 3.349 & 92.804 & & & \\
\hline 15 & .487 & 2.865 & 95.669 & & & \\
\hline 16 & .437 & 2.572 & 98.242 & & & \\
\hline 17 & .299 & 1.758 & 100.000 & & & \\
\hline
\end{tabular}


Table 3

Items correlation descriptive analysis of the mobile phone based application of COVID-19 test tool

\begin{tabular}{|c|c|c|c|c|c|}
\hline \multicolumn{6}{|c|}{ Item-Total Statistics } \\
\hline & $\begin{array}{l}\text { Scale Mean if } \\
\text { Item Deleted }\end{array}$ & $\begin{array}{l}\text { Scale Variance if } \\
\text { Item Deleted }\end{array}$ & $\begin{array}{l}\text { Corrected Item- } \\
\text { Total Correlation }\end{array}$ & $\begin{array}{l}\text { Squared } \\
\text { Multiple } \\
\text { Correlation }\end{array}$ & $\begin{array}{l}\text { Cronbach's Alpha } \\
\text { if Item Deleted }\end{array}$ \\
\hline COUGH & 12.67 & 2.802 & .562 & .425 & .726 \\
\hline SOB & 12.63 & 2.792 & .605 & .457 & .718 \\
\hline $\begin{array}{l}\text { Sore } \\
\text { Throat }\end{array}$ & 12.56 & 3.141 & .421 & .259 & .752 \\
\hline FEVER & 12.60 & 2.852 & .602 & .430 & .720 \\
\hline Anosmia & 12.50 & 3.155 & .547 & .372 & .736 \\
\hline Headache & 12.64 & 3.033 & .413 & .232 & .755 \\
\hline $\begin{array}{l}\text { Easy } \\
\text { Fatigability }\end{array}$ & 12.63 & 3.286 & .246 & .075 & .784 \\
\hline Vomiting & 12.50 & 3.272 & .410 & .203 & .754 \\
\hline
\end{tabular}


Table 4

Correlation finding in between symptoms of the mobile phone based application of COVID-19 test tool

Correlations

\begin{tabular}{|c|c|c|c|c|c|c|c|c|}
\hline & & COUGH & SOB & $\begin{array}{l}\text { Sore } \\
\text { Throat }\end{array}$ & FEVER & Anosmia & Headache & $\begin{array}{l}\text { Easy } \\
\text { Fatigability }\end{array}$ \\
\hline \multirow[t]{5}{*}{ COUGH } & $\begin{array}{l}\text { Pearson } \\
\text { Correlation }\end{array}$ & 1 & $.595^{\star \star}$ & $.255^{\star *}$ & $.532^{\star \star}$ & $.315^{\star *}$ & $.234^{\star \star}$ & $.237^{\star \star}$ \\
\hline & $\begin{array}{l}\text { Sig. (2- } \\
\text { tailed) }\end{array}$ & & .000 & .000 & .000 & .000 & .000 & .000 \\
\hline & $\begin{array}{l}\text { Sum of } \\
\text { Squares } \\
\text { and Cross- } \\
\text { products }\end{array}$ & 201.546 & 114.985 & 43.251 & 97.424 & 43.573 & 45.764 & 45.206 \\
\hline & Covariance & .201 & .115 & .043 & .097 & .043 & .046 & .045 \\
\hline & $\mathrm{N}$ & 1005 & 1005 & 1005 & 1005 & 1005 & 1005 & 1005 \\
\hline \multirow[t]{5}{*}{ SOB } & $\begin{array}{l}\text { Pearson } \\
\text { Correlation }\end{array}$ & $.595^{\star \star}$ & 1 & $.296^{\star \star}$ & $.555^{\star \star}$ & $.341^{\star \star}$ & $.263^{\star \star}$ & $.241^{\star \star}$ \\
\hline & $\begin{array}{l}\text { Sig. (2- } \\
\text { tailed) }\end{array}$ & .000 & & .000 & .000 & .000 & .000 & .000 \\
\hline & $\begin{array}{l}\text { Sum of } \\
\text { Squares } \\
\text { and Cross- } \\
\text { products }\end{array}$ & 114.985 & 185.274 & 48.070 & 97.562 & 45.159 & 49.323 & 44.224 \\
\hline & Covariance & .115 & .185 & .048 & .097 & .045 & .049 & .044 \\
\hline & $\mathrm{N}$ & 1005 & 1005 & 1005 & 1005 & 1005 & 1005 & 1005 \\
\hline \multirow[t]{5}{*}{$\begin{array}{l}\text { Sore } \\
\text { Throat }\end{array}$} & $\begin{array}{l}\text { Pearson } \\
\text { Correlation }\end{array}$ & $.255^{\star \star}$ & $.296^{\star \star}$ & 1 & $.265^{\star \star}$ & $.472^{\star *}$ & $.236^{\star \star}$ & $.121^{\star \star}$ \\
\hline & $\begin{array}{l}\text { Sig. (2- } \\
\text { tailed) }\end{array}$ & .000 & .000 & & .000 & .000 & .000 & .000 \\
\hline & $\begin{array}{l}\text { Sum of } \\
\text { Squares } \\
\text { and Cross- } \\
\text { products }\end{array}$ & 43.251 & 48.070 & 142.563 & 40.889 & 54.859 & 38.700 & 19.439 \\
\hline & Covariance & .043 & .048 & .142 & .041 & .055 & .039 & .019 \\
\hline & $\mathrm{N}$ & 1005 & 1005 & 1005 & 1005 & 1005 & 1005 & 1005 \\
\hline \multirow[t]{4}{*}{ FEVER } & $\begin{array}{l}\text { Pearson } \\
\text { Correlation }\end{array}$ & $.532^{\star \star}$ & $.555^{\star \star}$ & $.265^{\star \star}$ & 1 & $.372^{\star \star}$ & $.382^{\star \star}$ & $.163^{\star \star}$ \\
\hline & $\begin{array}{l}\text { Sig. (2- } \\
\text { tailed) }\end{array}$ & .000 & .000 & .000 & & .000 & .000 & .000 \\
\hline & $\begin{array}{l}\text { Sum of } \\
\text { Squares } \\
\text { and Cross- } \\
\text { products }\end{array}$ & 97.424 & 97.562 & 40.889 & 166.700 & 46.745 & 67.883 & 28.242 \\
\hline & Covariance & .097 & .097 & .041 & .166 & .047 & .068 & .028 \\
\hline
\end{tabular}




\begin{tabular}{|c|c|c|c|c|c|c|c|c|}
\hline & $\mathrm{N}$ & 1005 & 1005 & 1005 & 1005 & 1005 & 1005 & 1005 \\
\hline \multirow[t]{5}{*}{ Anosmia } & $\begin{array}{l}\text { Pearson } \\
\text { Correlation }\end{array}$ & $.315^{\star \star}$ & $.341^{\star \star}$ & $.472^{\star \star}$ & $.372^{\star \star}$ & 1 & $.398^{\star \star}$ & $.137^{\star \star}$ \\
\hline & $\begin{array}{l}\text { Sig. (2- } \\
\text { tailed) }\end{array}$ & .000 & .000 & .000 & .000 & & .000 & .000 \\
\hline & $\begin{array}{l}\text { Sum of } \\
\text { Squares } \\
\text { and Cross- } \\
\text { products }\end{array}$ & 43.573 & 45.159 & 54.859 & 46.745 & 94.820 & 53.315 & 18.003 \\
\hline & Covariance & .043 & .045 & .055 & .047 & .094 & .053 & .018 \\
\hline & $\mathrm{N}$ & 1005 & 1005 & 1005 & 1005 & 1005 & 1005 & 1005 \\
\hline \multirow[t]{5}{*}{ Headache } & $\begin{array}{l}\text { Pearson } \\
\text { Correlation }\end{array}$ & $.234^{\star \star}$ & $.263^{\star \star}$ & $.236^{\star \star}$ & $.382^{\star \star}$ & $.398^{* \star}$ & 1 & $.104^{\star \star}$ \\
\hline & $\begin{array}{l}\text { Sig. }(2- \\
\text { tailed) }\end{array}$ & .000 & .000 & .000 & .000 & .000 & & .001 \\
\hline & $\begin{array}{l}\text { Sum of } \\
\text { Squares } \\
\text { and Cross- } \\
\text { products }\end{array}$ & 45.764 & 49.323 & 38.700 & 67.883 & 53.315 & 189.309 & 19.337 \\
\hline & Covariance & .046 & .049 & .039 & .068 & .053 & . 189 & .019 \\
\hline & $\mathrm{N}$ & 1005 & 1005 & 1005 & 1005 & 1005 & 1005 & 1005 \\
\hline \multirow[t]{5}{*}{$\begin{array}{l}\text { Easy } \\
\text { Fatigability }\end{array}$} & $\begin{array}{l}\text { Pearson } \\
\text { Correlation }\end{array}$ & $.237^{\star \star}$ & $.241^{\star \star}$ & $.121^{\star *}$ & $.163^{\star \star}$ & $.137^{* \star}$ & $.104^{\star \star}$ & 1 \\
\hline & $\begin{array}{l}\text { Sig. (2- } \\
\text { tailed) }\end{array}$ & .000 & .000 & .000 & .000 & .000 & .001 & \\
\hline & $\begin{array}{l}\text { Sum of } \\
\text { Squares } \\
\text { and Cross- } \\
\text { products }\end{array}$ & 45.206 & 44.224 & 19.439 & 28.242 & 18.003 & 19.337 & 181.110 \\
\hline & Covariance & .045 & .044 & .019 & .028 & .018 & .019 & .180 \\
\hline & $\mathrm{N}$ & 1005 & 1005 & 1005 & 1005 & 1005 & 1005 & 1005 \\
\hline
\end{tabular}

\section{Discussion}

The new COVID-19 symptom screening test mobile phone based application tool has a high degree of sensitivity and a strong level of specificity. It has also better level of reliability, as demonstrated by the results, which the questions that are included as a screening item can capture and generate significant information regarding COVID - 19 infections. Further, it has also attractive level of ability in detecting true negative and positive results from those who have total negative and positive test results. Therefore, this mobile application was found to perform well in assessing the presence and absence of COVID-19 infection in the general population and an easy to administer as an instrument. 
RT-PCR assay is considered as a gold standard technique and still a fundamental method to be applied for the detection of SARS-CoV-2 to date. However, the current pandemic SARS-CoV-2 confuses the scientific and the medical community about which accurate diagnostic tool should be relied on to diagnose COVID-19 because of, the availability of few viewpoints that creates doubts as to underestimating its sensitivity and specificity (15). Therefore, due to its simplicity in utilization, the current application could be used in the screening of SARS-CoV-2. However, it might have some limitations that is usual to other screening methods, because current studies estimating test performance characteristics have imperfect study design and statistical methods for the estimation of test performance characteristics of SARS-CoV-2 tests like rRT-PCR and NAAT (16).

Regarding the percentage of validity, the current study finding is in line with the values obtained through the metaanalysis in its sensitivity, whereas it has lower level of specificity (17). However, even though the previous tests have high value of sensitivity and specificity in terms of detecting COVID-19 infection, it's worth noting that the difficulties and limitations described with respect to pathogen detection through molecular testing (real-time RT-PCR) are for the most part just as relevant to serological detection methods (18). Even though the sensitivity value of our finding is somewhat lower, but it has a higher level of specificity than the other meta-analysis finding report (19). In other words the current study identified high values of specificity than the previous similar attempt. Whereas, the combination of $\operatorname{lgM}$ and IgG antibodies, that demonstrated promising results for the parameters, sensitivity and specificity (19).

Different studies revealed that screening for only temperature is not sensitive enough to detect the vast majority of COVID $19(20,21,22)$. Our study result with respect to sensitivity for COVID 19 is far better than a temperature alone screening. This improved sensitivity is the result of combination of symptoms that led to detect patients who don't exhibit fever or cough.

In conclusion, the worldwide expansion of SARS-CoV-2 infection and the emergence of new strain have led to widespread adoption of symptom and risk screening measures. This mobile phone based application tool has a high level of sensitivity and a good degree of specificity in screening of COVID-19 related symptoms. Besides, the system doesn't have additional cost on anyone and accessible to most people at their convenient place. This screening tool is much better than only temperature screening which is found to be ineffective in most set up. An added benefit is this self-checker mobile application tool is helpful to help patients to sick medical help before they go to serious complication as the application reminds you about new symptom development for 14 days.

Therefore, the development of a friendly screening mobile application tool will definitely help in halting the spread of infection and early detection of disease and look for hospital care. Further, we strongly recommended that this tool can be used by the public to detect COVID 19 like symptoms prevalence in the community. It can also be used by different institutes to guide their staff and visitors to check themselves with this self-checker before they visit the institutions rather than using temperature screening alone.

\section{Abbreviations}

COVID-19; Coronavirus disease 2019

FMOH; Federal Ministry of Health

IgG; Immunoglobulin G

IgM; Immunoglobulin M 
PCR; polymerase chain reaction

SARS; Severe acute respiratory syndrome

SPHMMC; Saint Paul's Hospital Millennium Medical College

SPSS; Statistical Package for Social Sciences

WHO; World Health Organization

\section{Declarations}

\section{Availability of Data and Materials}

The datasets used and/or analysed during the current study are available from the corresponding author on reasonable request.

\section{Ethics approval and consent to participate}

The current manuscript had got ethical approval from St. Paul's Hospital Millennium Medical College (SPHMMC) IRB. In addition, informed consent was obtained from all study participants before they enrolled in the study. They were told that their participation is voluntary, and could withdraw at any time or refuse to answer any question if they wanted to. We used self-administered written questionnaires to maintain privacy. No information concerning the individual was passed to a third party. So, in general, we carried out the current research by fulfilling all the requirements of the institutional (SPHMMC) IRB guidelines and regulations and also it fulfilled the Declaration of Helsinki guidelines and regulations.

\section{Consent for publication}

Further, informed consent for publication was also obtained from each study participant under the consent form by mentioned for all of them that the data will be published in international journals. So, this is to confirm that informed consent for publication was obtained from all the study participants. The collected data is kept confidentially under the primary investigator and co-investigators.

\section{Competing interest}

All authors read and approved the final manuscript. The authors declare that they have no competing interests.

\section{Funding}

There is no source of funding for the current manuscript

\section{Authors' contributions}

MB and NT were involved starting from conceiving the idea, developing the proposal, the study design, reviewed the article, analysis, report writing, and drafted and write up of the manuscript; MA, AG and TS involved in developing the proposal, the study design, analysis, report writing and manuscript write up and review AL, TS and AG involved in data collection, data clearing, analysis and review of the manuscript. YB was involved in proposal development, data 
analysis, manuscript writing and editing the final manuscript. BT a software engineer involved in developing the mobile phone based screening application (telegram Bot), data cleaning and encoding, data analysis, and revision of the final manuscript.

\section{Acknowledgements}

The authors acknowledge St. Paul's Hospital Millennium Medical College institutional review Board (SPHMMC- IRB) for timely ethical evaluation and approval. The authors also acknowledge the staff of emergency, outpatient, and isolation departments of SPHMMC for their cooperation during data collection and the study participants for their willingness in providing the necessary information.

\section{References}

1. Guarner J. Three emerging coronaviruses in two decadesthe story of SARS, MERS, and Now COVID-19. Am J ClinPathol. 2020 Mar;9(4):420-1. 153(.

2. De Wit E, Van Doremalen N, Falzarano D, ., ; Aug. et al. SARS and MERS: recent insights into emerging coronaviruses [Internet]. 1. London: Nature Reviews Microbiology Nature Publishing Group; 2016. 523-34. Available from: www.nature.com/ nrmicro.

3. Hilgenfeld R, Peiris M. From SARS to MERS: 10 years of research on highly pathogenic human coronaviruses. Antiviral Res. 2013;100:286-95. [Elsevier].

4. Wang D, Hu B, Hu C, et al. Clinical Characteristics of 138 hospitalized patients with 2019 novel coronavirusinfected pneumonia in Wuhan, China. J Am Med Assoc. 2020;323(11):1061.

5. Huang C, Wang Y, Li X, et al. Clinical features of patients infected with 2019 novel coronavirus in Wuhan, China. Lancet. 2020 Feb 15;395 (10223):497-506.

6. Sasmita PA, ShaMeng Y-J, Wu Y-P, Mao R-X, Ye. and et al, Epidemiology, causes, clinical manifestation and diagnosis, prevention and control of coronavirus disease (COVID-19) during the early outbreak period: a scoping review,. Infectious Diseases of Poverty (2020) 9:29 https://doi.org/10.1186/s40249-020-00646-x.

7. Francesco D, Gennaro, DamianoPizzol C, Marotta M, Antunes V, Racalbuto. Nicola Veronese and Lee Smith, Coronavirus Diseases (COVID-19) Current Status and Future Perspectives: A Narrative Review. Int J Environ Res Public Health. 2020;17:2690. doi:10.3390/ijerph17082690.

8. Dong L, Hu S, Gao J. Discovering drugs to treat coronavirus disease 2019 (COVID-19). Drug Discoveries Therapeutics. 2020;14(1):58-60. https://doi.org/10.5582/ddt.2020.01012.

9. Wang D, Hu B, Hu C, Zhu F, Liu X, Zhang J, ... Zhao Y. Clinical characteristics of 138 hospitalized patients with 2019 novel coronavirus-infected pneumonia in Wuhan, China. JAMA. 2020;323(11):1061-9. https://doi.org/10.1001/jama.2020.1585.

10. Wu X, Cai Y, Huang X, et al. Co-infection with SARS-CoV-2 and influenza A virus in patient with pneumonia, China. Emerg Infect Dis 2020 Jun;26(6). doi:10.3201/eid2606.200299.

11. European Commission. EU Recommendations for testing strategies. 2020. Available here: https://ec.europa.eu/info/sites/info/files/covid19eu recommendations on testing strategies v2.

12. European Centre for Disease Prevention and Control. An overview of the rapid test situation for COVID-19 diagnosis in the EU/EEA. 1 April 2020. Stockholm: ECDC; 2020. 
13. Raquibel Mohammed Anwar. Neither tried nor tested. Dhaka Tribune Opinion /op-ed. May 04, 2020.https://www.dhakatribune.com/opinion/op-ed/2020/05/04/neither-tried-nor-tested.

14. Patrick FW, Chien KS, Khan. Evaluation of a clinical test. II: Assessment of validity. Br J Obstet Gynaecol. 2001;108:568-72.

15. Abdelmonem M, Ali AlfatihAboalbasherYousif, Ahmed O, Abuelhassan, Ebtehal M, fawzi, Sheima A, Elbasheer, Nagia S, Ahmed. Is a Real Time-Polymerase chain Reaction a Reliable Confirmatory Test for COVID-19? J Blood DisordTransfus. 2020;11:442. DOI:10.35248/2155-9864.20.11.442.

16. Dierdre B. Axell-Housea, RichaLavingiab,c,d, Megan Raffertyc,d, Eva Clarka,e, ES, Amirianc EY. Chiao, The estimation of diagnostic accuracy of tests for COVID-19: A scoping review, Journal of Infection 81 (2020) 681697.

17. IdevaldoFloriano AntônioSilvinato, Bernardo WM, Reis JC. Gabriel Soledade, Accuracy of the Polymerase Chain Reaction (PCR) test in the diagnosis of acute respiratory syndrome due to coronavirus: a systematic review and meta-analysis. REV ASSOC MED BRAS. 2020;66(7):880-8.

18. Clément, Bezier. GéraldineAnthoine, AbdérafiCharki, Reliability of real-time RT-PCR tests to detect SARSCov-2: A literature review. Int J Metrol Qual Eng. 2020;11:13.

19. Beatriz Boger MM, Fachi, Raquel O, Vilhena, Alexandre F, Cobre FS, Tonin. Roberto Pontarolo, Systematic review with meta-analysis of the accuracy of diagnostic tests for COVID-19. Am J Infect Control. 2021;49:21 - 29.

20. Katelyn Gostic, Ana CR Gomez2, Mummah RO, Kucharski AJ. James O Lloyd-Smith. Estimated effectiveness of symptom and risk screening to prevent the spread of COVID-19. eLife 2020;9:e55570.

21. Michel Bielecki GAndreaG, Crameri P, Schlagenhauf TW, Buehrer. Jeremy Werner Deuel. Body temperature screening to identify SARS-CoV-2 infected young adult travellers is ineffective. Travel Medicine Infectious Disease. 2020;37:101832.

22. Biswadev MITRA, Carl LUCKHOFF, Rob DMITCHELL, Gerard M, O’REILLY De. Villiers SMITand Peter A CAMERON .Temperature screening has negligible value for control of COVID-19. Emergency Medicine Australasia. 2020;32:867-9.

\section{Figures}




\section{COVID-19 test result}

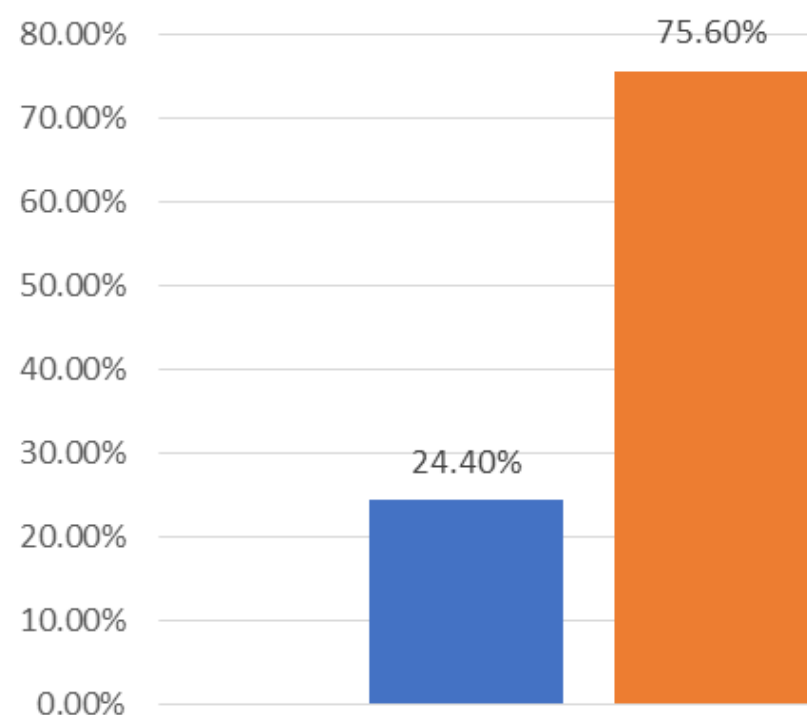

RTPCR test result
$59.40 \%$

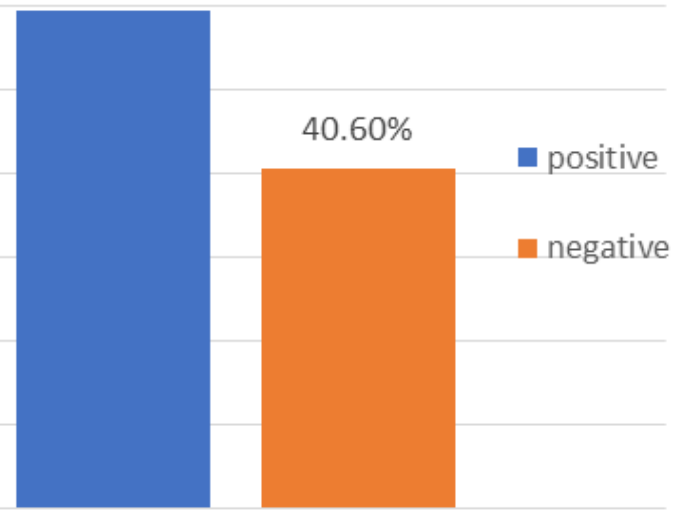

Mobile COVID-19 screening test result

\section{Figure 1}

COVID-19 test result of the study participants by using both mobile screening tool and gold standard, Addis Ababa, Ethiopia, 2020

\section{Validity result}

$100.00 \%$

$\begin{array}{r}90.00 \% \\ 80.00 \% \\ 70.00 \% \\ 60.00 \% \\ 50.00 \% \\ 40.00 \% \\ \hline 30.00 \% \\ \hline 20.00 \% \\ \hline 10.00 \% \\ \hline 0.00 \%\end{array}$

$46.40 \%$

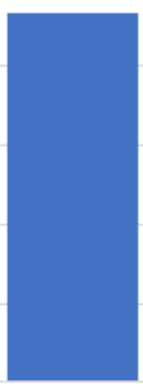

$31.60 \%$

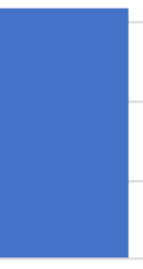

$86.50 \%$

\section{$77.60 \%$}

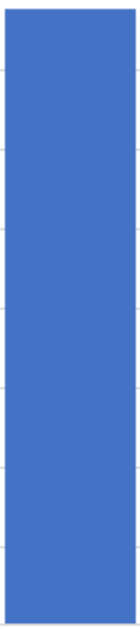

Sensitivity

specificity

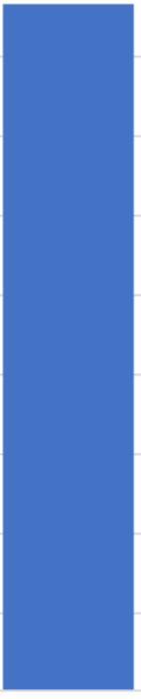

positive predictive value negative predictive value

\section{Figure 2}


validity result of the mobile phone based application of COVID-19 test tool

Page 15/15 